"This is the peer reviewed version of the following article: [Batista, M. d. G., Clegg, S., Pina e Cunha, M., Giustiniano, L. and Rego, A. (2016), Improvising Prescription: Evidence from the Emergency Room. Brit $J$ Manage, 27: 406-425 ]which has been published in final form at [ http://dx.doi.org/10.1111/1467-

8551.12143 ]. This article may be used for non-commercial purposes in accordance with Wiley Terms and Conditions for Self-Archiving." 


\title{
IMPROVISING PRESCRIPTION: EVIDENCE FROM THE EMERGENCY ROOM
}

\begin{abstract}
Global medical practice is increasingly standardizing through evidence-based approaches and quality certification procedures. Despite this increasing standardization, medical work in emergency units necessarily involves sensitivity to the individual, the particular, and the unexpected. While much medical practice is routine, important improvisational elements remain significant. Standardization and improvisation can be seen as two conflicting logics. However, they are not incompatible although the occurrence of improvisation in highly structured and institutionally complex environments remains underexplored. The study presents the process of improvisation in the tightly controlled work environment of the emergency room. We conducted an in situ ethnographic observation of an emergency unit. Using an inductive approach, we see professionals combining ostensive compliance to protocols with necessary and occasional "underlife" improvisations. The duality of improvisation as simultaneously present and absent is related to pressures in the institutional domain as well as to practical needs emerging from the operational realm. The intense presence of procedures and work processes enables flexible improvised performances that paradoxically end up reinforcing institutional pressures for standardization.
\end{abstract}

Keywords: improvisation, intuition, healthcare, dialectics, bureaucracy, institutional complexity, institutional logics. 


\section{INTRODUCTION}

Physicians interpreting the nature of patients' illnesses have to integrate multiple pieces of information into a pattern when they make a diagnosis and prescribe treatments. Sometimes they have to enact these routines in the context of unexpected and non-routine situations. The emergency room, in particular, is a context in which routines need to be varied and scripts improvised as events unsettle procedures; thus, it makes a promising setting for the study of improvisation in an institutional environment that is, by and large, highly prescribed rather than improvised.

With the emergency room context in mind, we formulate our research question as follows: How does improvisation unfold in a tightly standardized bureaucratic environment? We approach our research question inductively, exploring the process of improvisation in a hospital emergency room. In general, hospitals are highly bureaucratic organizations, relying on professional standardized skills inculcated mostly outside the organization (Mintzberg, 1983), operating via the extensive use of clinical guidelines (also variously called protocols, recommendations, algorithms, parameters) that are increasingly pervasive (Adler and Kwon, 2013). On the other hand, physicians, as professionals, have the autonomy and responsibility to provide individualized care for their patients, adjusting and improvising treatments in response to situational uniqueness (Vogus et al., 2010) as they enact improvisations in changing clinical circumstances (Weick 1988, 1990).

A requirement for adherence to the rules and the practical exigencies of the need for improvisation might well conflict with each other in organizational fields characterized by institutionalized norms of accountability (Brickerhoff, 2003), particularly in contexts characterized by a high degree of institutional complexity (e.g. McPherson and Sauder, 2013; Besharov and Smith, 2014) due to the highly professionalized and institutionalized knowledges that have to be managed. Such management is 
usually done through deference to rules. Much less attention has been paid to the micro-level mechanisms describing how individuals experience and manage such complexity (Kraatz and Block, 2008) compared to conflicts between macro-level institutions. In order to fill this gap we report behaviours that when contrasted with guidelines and protocols might be considered as "extremes", "deviations" or "outliers". We seek to display how clinicians use institutionalized logics in extreme cases while improvising as they engage in emergency care. In particular, while institutional theory supposes that professionals comply and adhere to macro-level overarching logics, we describe how improvisation might unfold, in a tightly regulated field, via different forms and through different behavioural strategies, including ostensive compliance and "underlife" improvisation. We contribute to the improvisation literature by extending its study to the bureaucratic context, showing that bureaucracy does not necessarily restrain improvisation but can shapes its use and formal expression. We begin by situating conflicting logics in medical practice.

\section{CONFLICTING LOGICS IN MEDICAL PRACTICE}

Conflicting institutional logics have been understood variously as "the sensemaking frames that provide understandings of what is legitimate, reasonable and effective in a given context" (Guillén, 2001, p. 14); as the "belief systems and related practices that predominate in an organizational field" (Scott, 2001, p. 139); as the "taken-for-granted rules guiding behaviour of first-level actors" (Reay and Hining, 2009, p. 629); as the "organising principles that shape the behaviour of the field participants" (Reay and Hinings, 2009, p. 631). In whichever of these related ways on understanding them institutional logics are endemic to the field of healthcare (Kraatz and Block, 2008) in which different logics co-exist or compete against each other (e.g. D’Aunno, Succi and Alexander, 2000; Denis, Lamothe and Langley, 2001; Dunn and Jones, 2010; Guillén, 2001; Reay and Hinings, 2009). Clinical health care, comprising many 
professional identities enjoying considerable elements of indeterminacy (e.g. McPherson and Sauder, 2013; Raaijmakers et al., 2015), is situated in a tension between evidence-based practice normatively institutionalized and individualized considerations made in on the spot judgements (Haidet, 2007; Janicek, 2006; Naylor, 2001; Shaughnessy et al., 1998). On occasion, there is a need for "organizational legitimacy" to be established between these if they are construed as conflicting logics (Kraatz and Block, 2008; Mykhalovskiy and Weir, 2004).

Medical practice, in theory, is a field dominated by the logic of heavily regulated routines, which are replicable and rational (Elmore et al., 2005; Hiyama et al., 2006; Sharma et al., 2003). Practices of clinical guidelines, organizational certifications, accepted best practices and evidence-based medicine (e.g. Sackett and Rosenberg, 1995) frame the field. Such professionalized framing marginalizes physicians' reliance on intuition and experience-based improvisations. Physicians allegedly operate in what has been labelled a Taylorized, "evidence-based everything" environment (Mykhalovskiy and Weir, 2004, p. 1060). At the same time, medicine enjoys a high degree of professionalization in the sense of being practised by personnel who have rules built into them through the processes of their professional training (Perrow, 1984). In light of this relative autonomy, some scholars describe medicine as both "an art and a science" (Garfield and Garfield, 2000; Kenny, 1997; Saunders, 2000). Haidet (2007), for instance, used the metaphor of jazz to describe the "art of medicine" (see also Miller et al., 2001). As such, medicine in practice may require considerable improvisational adjustment rather than merely the repetition of rigidly scripted performances (Tucker and Edmondson, 2003; Weick and Sutcliffe, 2003).

Discussions of evidence-based medicine (EBM) and its implications for medical practice are heterogeneous (e.g. EBMWG, 1992; Morrell, Learmonth and Heracleous, 2015). At a wider 
epistemological level, EBM is seen as a conception of "scientific knowledge" (e.g. Feinstein and Horwitz, 1997; Marshall, 1997) that stresses a positivist conception of prescription, implying a shift to a paradigm that "de-emphasizes intuition, unsystematic clinical experience, and pathophysiologic rationale as sufficient ground for clinical decision making" (EBMWG, 1992, p. 2420), albeit that it is expected to be able to "provide superior patient care" (EBMWG, 1992, p. 2421). In this vein, EBM might be posited managerially as a "source of belief", through which "every [doctor] assumes about all the others what, without believing it himself, he learns about the belief of the others" (de Certeau, 1984, p. 189). In fact, the idea of "scientification" of medicine as a "source of belief" à la de Certeau (1984) leads to the creation of overarching logics operating at the macro-level (e.g. Greenwood, Hinings and Whetten, 2014; Guillén, 2001). ${ }^{\mathrm{i}}$

In many countries the escalation of healthcare costs has enhanced awareness of the need to eliminate costly process variation through the institutionalization of health standards and guidelines as a way of establishing efficiencies as well improving the overall quality of health systems (e.g. Barros and Simões, 2007; Ferlie and Shortell, 2001; Woolf et al., 1999). The development of EBM-based guidelines, protocols and operational standards via the incorporation of evidence from clinical trials is supposed to guarantee the basis of doctors' behaviours (practice) and the quality of care. In the medical field, standards, routines, protocols and guidelines are all oriented to "average cases", built around single pathologies, symptomatologies or patient paths. Protocols and guidelines are transferred internationally, either via their adoption as operational standards for whole national health systems or via the alignment of clinicians to the state of the art in their professional communities. Transfer is based on the assumption that similarities in terms of medical specialities are more relevant than differences in national health systems and the characteristics of the single "hosting" hospital in institutional interpretation (e.g. Greenwood, Hinings and Whetten, 2014; Meyer and Höllerer, 2014). Knowledge routines are 
institutionalized via the action of coercive (national state regulated health systems) as well as normative (professional communities) isomorphism (DiMaggio and Powell, 1983). Despite the dominance of protocols and guidelines in national regulation and professional practice, "knowledge gained from clinical research does not directly answer the primary clinical question of what is best for the patient at hand" (Tonelli, 2001, p. 1435) when situated judgements have to be made. In fact, as in other knowledge-intensive settings, knowledge can be codified in routines (such as protocols), expressed in tacit ways or collected from larger communities and networks in the form of meta-knowledge (e.g, Evanschitzky et al., 2007). Clinicians may be forced by the actual conditions of patients to utilise different "pieces" of knowledge embedded in protocols, combine them, or activate expertise and experience via intuition (e.g. Feder et al., 1999; Nicolini, 2010).

It is the nature of situated practice that creates conflict between the dominant logic of heavily regulated EBM-oriented routines and the professional logic of independent, indeterminate and tacit judgement. On the one hand, the existence of EBM-oriented overarching logics operating at a macro-level enables the production of frames of action (meso-level accounts), based on the "average case", a statistical artefact rather than sociologically meaningful category (e.g. de Certeau, 1984). On the other hand, the enactment of micro-level accounts of compliance with such external standards may constrain the "proficiency and the judgement that the individual clinicians acquire through clinical experience and practice" (Sackett et al., 1996, p. 71). In this vein Tonelli (1999) advises that "rather than the lowest form of empirical evidence, expert opinion could easily be viewed as the highest form of clinical experience and judgment" (p. 1188). So, despite the prescriptiveness of EBM, clinicians might rely also on improvisation in their micro-level decisions and activities, i.e. in their day-to-day, or better case-by-case, decisions and activities. 
Improvisation has been studied as an unplanned but intentional response to events that are unexpected and unpredictable (Weick and Sutcliffe, 2007). Professional routines in hospitals seek to minimize the occurrence of such events; however, in some areas of healthcare, such as the emergency room, the flow of events necessarily creates unexpectedness. In such a context, understanding how particular processes of improvisation are used to tackle unexpected events is a vital part of training in an otherwise highly regulated field of practice. As Kaplan and Porter (2011, p. 58) have documented, there are "significant variation in the processes, tools, equipment, and materials used by physicians performing the same service within the same unit in the same facility." So, compliance to standards (bureaucracy) and improvisation can be considered as meso-level logics framing and influencing organizational activity. While one logic is inspired by standardisation and bureaucratic and commercial controls of the medical profession (Adler and Kwon, 2013), medical practice necessarily involves attention to the unexpected and the surprising, potentially forcing clinicians to deviate from prescription and to rely on improvisation, defined as spontaneously responding to the unexpected with available resources (Cunha, Cunha and Kamoche, 1999; Cunha, Miner and Antonacopoulou, 2016; Faraj and Xiao, 2006; Hadida and Tarvainen, 2014; Moorman and Miner, 1998a). So clinicians exercise a great deal of autonomy in their use of logics. Nowhere is this more the case than in the emergency room.

\section{FRAMING THE LOGIC OF IMPROVISATION IN THE EMERGENCY ROOM}

While the stress on bureaucratic control and the elimination of process variation through standardization, routinization and training is a central feature of medical professionalization in hospital emergency rooms, improvisation is often defended as necessary to handle unexpected events and situations (Argote, 1982; King and Ranft, 2001; Miller et al., 2001), even in the form of "epistemic contestation" (Faraj and Xiao, 2006). While EBM rules the prescriptive spaces of medicine, Vogus, Sutcliffe and Weick (2010, 
p. 67) note that the resilience capabilities needed to create safety cultures in hospitals "include greater skill at improvisation, learning, multitasking and adapting." Improvisation, less emphasized but relevant in many situated sites of medical work (Hadders, 2009; Haidet, 2007; Kirmayer, 1994; Miller et al., 2001; Shaughnessy, Slawson and Becker, 1998) is especially important in the emergency room, where working under acute time pressures, being able to separate planning and execution can be a practical impossibility (King and Ranft, 2001). In these situations an inability to improvise can put the patients' health and life in danger (Manner, 2007; Studdert et al., 2005; Summerton, 1995). The emphasis on improvisational actorhood (e.g. Meyer and Höllerer, 2014) privileges intuition and intentional spontaneity.

The emergency room is a setting with organizational space for improvised action (Brown and Eisenhardt, 1997; Kamoche and Cunha, 2001). Haidet (2007, p. 168) argues that "physicians must be skilled improvisers" in order effectively to handle patients' unique idiosyncrasies as deviations from the "average case". The main sources of patient variability in emergency care are age, severity of the case, comorbidity, acuity of the major symptoms, level of consciousness at the intake, presence of other latent or neglected conditions (e.g. Welch et al. 2011). Because clinician-patient encounters are often relatively unscripted and constructed "in the moment" (Shaughnessy et al., 1998), a patient-centred care ideal does not just require following biomedical patterns of inquiry (Roter et al., 1997) but also entails "adjustments to and departures from these patterns in response to concerns and perspectives voiced by the patient" (Haidet, 2007, p. 164). ${ }^{\text {ii }}$

According to EBM in its founding manifesto (EBMWG, 1992), individual (medical) intuition should be de-emphasised in favour of literature-based investigation and compliance with guidelines and protocols. Nonetheless, although it arises through swift, unconscious, and holistic associations, intuition is different 
from mere instinct or insight. In fact, intuition implies judgment and embeds domains of knowledge, implicit and explicit learning (e.g. Burke and Miller, 1999; Dane and Pratt, 2007). Similarly, improvisation is not just the execution of unplanned actions so much as a dialectical synthesis of prior planning and acting in the moment (Clegg, Cunha and Cunha, 2002). Intuition can be explained as improvising that implicitly (or even unconsciously) benefits from previous actions. Such a synthesis is an enduring practice of emergency medicine (e.g. Langley et al., 2013).

Hadida and Tarvainen (2014) summarize organizational improvisation as spanning from the individual to the organizational level (individual, interpersonal, organizational) along different degrees of magnitude (minor, bounded, structural). At the individual level, improvisation happens when “employees adjust their work in real time to emerging information or are stretched beyond their routines to deliver a novel solution to the problem" (Hadida and Tarvainen, 2014, p. 11). In this vein, individual improvisation (micro improvisation) takes place as an "ad hoc" action to accomplish work (Cunha, Clegg and Kamoche, 2006; Cunha, Cunha and Kamoche, 1999).

Medical work, in practice, although highly systematic, is also likely to be an equivocal trial-and-error process rather than a purely rational science (Edmondson, Bohmer and Pisano, 2001) and involves impromptu action in both diagnosis and treatment (Battista et al., 1995; Garfield and Garfield, 2000; King and Ranft, 2001; Malterud, 2001; Naylor, 2001). In particular, these tendencies are most evident in emergency care, where actors engage in "ad hoc baseline improvisation", in which at least some of the activities in an action pattern can be seen as novel and distinct from prior enactments (Cunha, Miner and Antonacopoulou, 2016). The emergency room is considered to be an appropriate research setting since unexpected events potentially trigger improvisation in contexts where forms of action established in clinical guidelines may be neither relevant nor contemplated (Moorman and Miner, 1998b). Emergency 
situations are categorized as important, urgent, and difficult events (Crossan and Sorrenti, 1997) that cannot be fully standardized. In summary, the emergency room may be characterized by the predictable interplay of improvisation and bureaucracy within a context in which the bureaucratic logic is dominant. To research these ideas we conducted a study in a Portuguese hospital, using several methods to collect data.

\section{METHOD}

Central strategies for collecting data were ethnographic observational methods, interviewing, and daily interactions, including countless informal conversations with which we sought to explore the phenomenon of interest. We used observation to surmount limitations associated with interviewing (Alvesson, 2003), and interviewing in order to overcome limited technical knowledge of medical work and its specialist discourses. Our analysis and theoretical framing followed the precepts of ethnographic grounded theorizing (Suddaby, 2006). Methodologically, we proceeded in waves of data collection and analysis. As in many qualitative projects (e.g. Sonenshein et al., 2014), we proceeded in a succession of iterations (October 2004 to March 2013; see Table 1), in periods of different observational intensity. Given the elusive nature of the topic, the process of shared reflection between authors and informants presented itself as a recursive alternative richer than other methodological possibilities. The approach was made feasible by building social capital through interactions with informants, creating relationships as "resources for action" (Gittell and Douglass, 2012, p. 711). In the absence of such relational resources, longitudinal access to the research site would have been difficult to sustain.

After consulting the hospital ethics committee, the hospital board authorized access to the emergency service. Permission was granted to gain access to designated areas and to observe authorized interactions between doctors and patients provided that: (1) total confidentiality; (2) non-intervention, and (3) no 
opposition from the doctor or the patient. For confidentiality reasons, codes were assigned to physicians (e.g. MD01) and nurses (e.g. NU01). A timeline of the field research, conducted by the first author in a sequence of six waves, is indicated in Table 1. As anticipated in the Introduction, the most significant evidence and quotes reported in the paper are taken from the "extremes" or "deviations" (outliers) against the norm to stick to the guidelines and protocols.

\section{INSERT TABLE 1 ABOUT HERE}

From first-order themes to third-order categories. The analysis of the data led to the consideration of seven first-order themes, which gave rise to four second-order themes, subsequently organized into two third-order categories (Figure 1). The patterns emerging from the first-order codes disclosed the informants' meaning systems that were used as the basis for the definition of second-order themes by combining information (Locke, 2001) and establishing a higher level of theoretical abstraction. Constant comparison (Corbin and Strauss, 1990; Strauss and Corbin, 1998) between data and theory was used until conceptual categories matured and stabilized. Literature on medical practice, improvisation (e.g. Cunha, Clegg and Kamoche, 2006), and related constructs (e.g. defensive medicine, EBM, routines, organizational memory, and learning; Chiva and Alegre, 2009; Ebbers and Wijnberg, 2009) provided the conceptual foundations for the organization of the incidents into broader analytical categories.

\section{INSERT FIGURE 1 ABOUT HERE}

Four second-order themes, emerging from the first-order themes, represent an intermediate level of conceptualization. According to informants the first second-order theme, "Professional scrutiny", articulates two first-order themes: (1) the increasing media visibility of medical practice; (2) the legalistic environment in which the profession is now practiced. The second second-order theme, 
"Protocol-based practice", synthesizes the pressure for the adoption of professional best practice in the context of the hospital's certification process, as well as the widespread adoption of medical protocols which regulate medical practice. The third second-order theme, "Patient variability", captures the fact that patients respond differentially to treatment. The theme represents the opposite of the pressure for the adoption of protocol-based action by alerting us to the essential event and patient-based contingency of clinical practice. The final theme, "Improvisation around protocols", refers to the necessity of improvisation. It exists, in the words of some informants, as the result of the need to respond spontaneously, rapidly and in situ, often requiring the use of tools and techniques in an improvised way.

These four intermediate categories were finally synthesized in two overarching categories that exist interdependently, postulated as a permanent relational dialectic (Clegg, Cunha and Cunha, 2002). These were (1) "ostensive compliance" and (2) "underlife improvisation" (Figure 1). "Ostensive compliance" captures the deliberate attempt by professionals to be seen to apply and respect protocols. "Underlife improvisation" refers to improvisational adaptations taking place in the informal and less visible underlife of situated actions. These improvisations are without trace in the formal bureaucratic façade, and therefore formally non-existent. These two final dimensions articulate the phenomena revealed by the data and capture the overarching concepts relevant to the performance in the emergency room. The rivalry of logics revealed by the final pair of opposites articulates a dual tension: it allows for improvisation while pushing it to the organization's underlife, reinforcing the formal façade of compliance, while simultaneously challenging it and creating conditions for resistance.

\section{FINDINGS}

Overall, we found and modelled the co-existence of two forces. One refers to improvising while translating intuitions and personal expertise into enacted decisions and actions, resulting from the nature 
of medical practice itself. The latter is the result of complying with the extant guidelines within the logics of EBM. In such a bureaucratic environment, even well intentioned and reasoned improvisation may be seen as a dangerous departure from that which is formally defensible and protected by compliance with standard operating procedures (e.g. Weick, 1988; 1990). In most of the world, in case

of lawsuits, strict adherence to guidelines is required to protect physicians from accusations of malpractice. So even in healthcare systems in which a "no-blame culture" is promoted and defended, deviation from guidelines could revert the burden of proof (of innocence) against practitioners (Halligan and Donaldson, 2001). To this extent, compliance with procedure can at times become more important than the treatment because a treatment supported by a procedure is defensible whereas improvisations responding to the unexpected may be indefensible from a formal point of view.

\section{The enactment of improvisation in the emergency room}

EBM discourse institutionalized guidelines referring to the "modalities of action" and "formalities of practices ... [as]... areas of activities that flow together" (de Certeau, 1984, p. 29). In dealing with an emergency situation, practice can be seen as an "enactment" of individual intuition against compliance with standards (Weick, 1998). Such behaviour can threaten personal professional identity when the "sense" made by protocols breaks down (e.g. Weick, 1990) and influences individual behaviours (e.g. Cornelissen et al., 2014; Weick, 1993).

The "extreme cases" in our evidence display a dynamics of sensemaking and sensebreaking that we can arrange in terms of four major second-order categories: (1) professional scrutiny, (2) protocol-based practice, (3) patient variability, and (4) improvisation around protocols. 
Professional scrutiny. The growing media interest in medical situations (especially cases with a negative outcome), together with changes in patients' perceptions of physicians' performance, have increased public scrutiny of the medical profession. Our data reflects such trends. ${ }^{\text {iii }}$

There were evident signs of increased public disquiet and scrutiny. Lawsuits against physicians concerning the facts of particular cases, an indicator of a progressively legally adversarial society (Pfeffer, 1994), have increased. Some behaviour in media and legal arenas (including physical aggression, threats of lawsuits, and threats of media exposure) seems designed to intimidate professionals. Extreme cases were witnessed during observations. On one occasion, a man claimed that an assistant physician had not spent enough time examining his daughter and threatened to file an administrative complaint against the physician. In another case, a man threatened to go to the media because he thought the waiting time for the result of his diagnosis was too long. In a third situation, a patient threatened to assault a medical assistant. These behaviours are far from specific to the hospital researched or to the Portuguese national health system. The medical journal The Lancet (2012) notes their international prevalence. Our informants demonstrated strong awareness of the fact that every clinical case that goes wrong potentially will attract media coverage. As explained by one clinician, "almost all news is about errors or negligence; it is difficult to find positive [medical] features in the media" (MD05). Other informants observed the following: (a) "Journalists are very aggressive, they assume that the physician or the hospital is guilty, mistakes are definitely the physician, administrative, or hospital fault [the] media induce those behaviours" (MD06); (b) "We now feel external interference related to medical intervention. The media is pushing people, anyone can complain publicly; this has a cascading effect among people and is reflected on the physician's attitude" (MD08). A panoptical world in which doctors feel themselves constantly observed has been created through added transparency and scrutiny. 
Since mistakes have the potential to harm a career, physicians need to take care in their professional relationship with patients. Even in cases where national health systems or specific hospitals do not prescribe a set of specific guidelines, intense scrutiny of the clinical context facilitates the tendency to follow international protocols for protection or justification in case of a legal process. In this vein, the role of international protocols might shift from normative isomorphism (DiMaggio and Powell, 1983) towards affording protection against coercion. As one informant put it: "In $90 \%$ of the cases, there is no justification to use that protocol. The problem is, if the patient dies and I have to go to court, well, I've done everything that the protocol states" (MD33). Protocols were sometimes followed for performative rather than for substantive medical purposes, which strongly discourages improvisation, as professionals may end up perceiving that it is better to do things right than to do the right things. This leads us to develop the following propositions:

Proposition 1a: The growing scrutiny of medical work increases the ritual adoption of medical protocols, discouraging improvisation.

Proposition 1b: The perceived legal consequences of non-compliance increase the ritual adoption of medical protocols, discouraging improvisation.

Protocol-based practice. The second theoretical category, "protocol-based practice", refers to efforts by staff members to follow an established set of rules (i.e. international best practices) determined by accredited processes (Cook et al., 1983; Smith and Mick, 1985) as well as maintaining a cooperative environment among team members. 
In Portugal, accredited hospitals offer an institutional assurance of service quality. So, patient risk is transferred to the hospital, which provides operational protection against possible malpractice lawsuits. Medical acts performed by physicians are supposed to follow pre-determined rules, with pre-specified information recorded in patients' files (e.g., time of first consultation, symptoms, lab tests, general impressions) in pre-formatted sheets that provide, according to one of our informants, "evidence that everything we did was correct" (MD27).

Retrieval mechanisms simultaneously provide information and protection. They advance useful information that restricts possible negative personal and institutional consequences related to medical performance arising when performing one's duties. When necessary, they allow physicians to justify that their actions were accurate and "by the book". As our informants' stated, "we construct a legal document according to hospital rules and it contains a pre-determined set of information." (MD03). Doctors explicitly tried to leave a trace of their decisions for the record.

Patient variability. A further second-order theoretical category, "patient variability" encompasses the "trial-and-error" component of medicine and the idea that diseases and their clinical expression assume a diversity of individual manifestations. Evidence of "patient variability" emerged from both the observations and the interviews. As an informant put it, "the way a disease is going to manifest in an individual is different from how it is displayed in another person. It is not something that we can do 'copy/paste'." (MD03). Another participant explained, "in medicine we have to deal with the unpredictable because every individual that has the same disease is going to present symptoms and react [to the treatments] in their own way." (MD08). One doctor mentioned the case of a patient "whose tests did not show anything unusual. The ECG did not show any changes. He had just some arrhythmias. The following test was not conclusive. I could have sent him home to take his usual medications but the 
patient was always mentioning that he was tired, then I decided to fast forward the process and made him an additional test and he went to surgery so I 'escaped' the guidelines and the patient is now well. I took a chance and it was the best for the patient." (MD37). This category therefore indicates that pressure towards conformity does not neutralize the emergence of individualized procedures raised by the diversity of individual expressions of medical problem. Protocols establish uniform approaches to non-uniform problems that may require special procedures outside the "average case". The plurality of sources for the enactment of sensemaking and consequent action might reveal conflicting logics between different protocols/guidelines created around different criteria for stratifying patients (e.g. age, pathology, symptomatology) and between them and improvisations around intuition. In this sense, doctors might apply different pieces of knowledge embedded in protocols and individual clinical experience as their "baseline" for ad hoc improvisation (Cunha, Miner and Antonacopoulou, 2016).

Proposition 2: The singularity of each clinical case limits the absolute validity of formal procedures and indicates the need for individualized consideration of patients and for customized professional responses, sometimes improvised ones.

Improvisation around protocols. Improvisation arises "around" protocols when structures reveal themselves solid enough to make practice predictable but also flexible enough to support behavioural variation. As one informant said, "procedures are very, very much routinized." (MD34). And he added that "99\%" (MD34) of the cases involve some pre-established procedure.

Bureaucracy is used for protection, as previously discussed. We found this when doctors made telephone calls to the Anti-Poison National Centre, after their action and just for the record. Novices, especially, use rules for protection. Weick (1995) noted that wisdom, as a mixture of knowledge and ignorance, involves both (a) respect for acquired knowledge as contained in standards, and (b) the adaptation of 
action to situations not anticipated by the rules, as expressed through improvisation. As one physician [MD35] explained, "younger physicians have a tendency to request a large number of complementary diagnosis tests, acting as exam prescribers". But rules are also used to support informal improvisations when physicians engage in the initial conversation with patients with a consciousness or language disturbance. Novices also emerged as distinct users of this function: they would never act without the endorsement of the team leader and would include into the patient file the reference "according to the directions of Dr. A".

The structural flexibility permitted by bureaucracy accommodates the singularities of each clinical case while simultaneously complying with general rules. Some evidence emerged in the following way: "Although situations are not always the same, there are variations and these protocols cannot be applied, (...). It is an aid tool." (MD08). Another physician was more explicit about the potentiality for improvisation: "I have eighteen years of experience and you always improvise. You constantly improvise" (NU01). Bureaucratic structures therefore meet two requirements: (a) they contribute to preserve performance adaptation, while (b) providing protection against external scrutiny. Professionals in the emergency room accommodate this double perspective in different ways. Bureaucratic protocols work as "reminders" to meet the need for effective performance (e.g. communications with the AntiPoison National Centre), and they are used as protection devices through several forms of records (e.g. at the hospital call centre; lab tests or X-rays requisitions). They provide protection (for both novices and experts) but also support individualized consideration via improvisation around the protocol (mainly for experts rather than novices).

The patient's clinical record and complementary diagnostic exams (e.g. X-rays, blood tests), which are added to the clinical records, allow the same document (in written or digitalized format) to serve the 
dual purpose of recording improvisation and being seen to accord with protocols. Although variation is possible, it is supported by procedures that signal the adequacy of the formalized guidelines even if their substantive value is low. They serve to create a façade behind which improvisation can take place, screened by protocols.

A physician can ask for complementary tests without seeing the patient, using the information from triage. However, once it has been requested and recorded in the patient's file, it will be considered as if the physician followed the procedures and did not avoid the initial step of engaging in a conversation with the patient and conducting a physical exam. Contextual pressures for conformity may deliver benefits for both physicians and patients. As for downsides, the most relevant was the extensive use of support equipment and the associated costs resulting from the proliferation of examinations for performative rather more than substantive reasons. In such cases improvisation takes place around the protocols exploiting the diachronic space between the actual time of decision and action and ex post legitimation via formalization (e.g. Kraatz and Block, 1998). In this way, improvised enactment reveals itself as a reworking of pre-composed material, influenced by unanticipated factors in the wider frame of the conception of action as it unfolds (Cunha et al., 1999). In doing that over time, doctors might develop some regular patterns of behaviours informing learning for future improvisation. In this vein, intuition enacts actions driven by previous experience and knowledge while anticipating the creation of knowledge to be used later.

The availability of immediately expendable knowledge is a key point here. While less experienced doctors stick to the protocols, more experienced ones may express a less defensive approach to medical practice. From this we extract the following: 
Proposition 3: The growing adoption of clinical protocols leads both to (a) the increasing adoption of formal procedures of ostensive compliance in medical acts, and (b) the adoption of improvised actions by more experienced doctors under the façade of formal best practice.

\section{Deriving Third Order Concepts}

Close observation of medical practice in the emergency room and a careful analysis of data collected from the several sources consulted enabled us to construct two aggregated third-level, conceptually deeper theoretical, dimensions: (1) "ostensive compliance", i.e. the explicit communication of rule following, and (2) "underlife improvisation", i.e. the discrete adoption of case-based improvised approaches. These dimensions coexist and dialectically sustain each other. Each fulfils a different purpose in response to the particularities of medical practice in a dual sort of relationship (Farjoun, 2010): one focuses on the figure of the patient and the other on the organizational system and the figure of the professional (Figure 2). They mutually nurture each other, enhancing the magnitude of the dual role of bureaucracy.

\section{INSERT FIGURE 2 ABOUT HERE}

Ostensive compliance and underlife improvisation are enacted simultaneously to meet two goals: (1) minimizing legal risk associated with the scrutiny of medical profession, reflected in defensive types of medical practice; (2) legitimating practice via the assurance that medical performance is aligned with established scientific evidence. As such they constitute two distinct logics in action. Medical work in the emergency room applies a number of standard procedures that start with the registration of the patient and end with the treatment. When this contact begins, the process usually follows a pattern of inquiries about the symptoms, medication in use, complementary diagnosis tests, providing information 
supportive of diagnosis and therapeutics. The set of routines also establishes how to register relevant information in the patient's individual record.

These routinized procedures both support and inhibit improvisation. They support improvisation by offering sanctuary for deviation such as when a doctor can follow a "step-up" or "step-down" therapeutic approach i.e., starting the therapeutic intervention with the minimum amount of drugs and adjusting them, or starting with a large amount of drugs and decreasing them, depending on reactions. Sensemaking around individual action is nurtured when the sense embedded in protocols is breaking down (Weick, 1988; 1993; Cornelissen et al., 2014). They inhibit improvisation when used for protection, as happens when patients are in serious life threatening conditions, such as cardiac arrest or severe trauma. In this sense, structure, rather than being an externally imposed constraint, should be seen as both external and enacted, as cognitively produced (Sagiv et al., 2009), offering a space for improvisation to be activated or inhibited.

Medical practice involves a dual appropriation of routines by professionals. On the one hand, protocols are fixed, offering prescribed procedures. On the other hand, they incorporate possible variations that tend to be missed in formal accounts of the clinical protocol. At the initial stages of our observation, only the visible and explicit side of routines emerged. As a lay observer, one could predict the procedures that were going to be used. With time and through repeated interactions with professionals, it became possible to apprehend the improvisation that was happening beneath the surface of the ostensive component.

When EBM protocols are absorbed by national healthcare systems as de facto or ex lege standards, they are transmitted to institutions; here they help to protect physicians against professional liability legal claims. Younger clinicians receive support from more experienced colleagues that helps them gradually 
to introduce variability and to feel more confident with improvisational moves, exposing them to canons of good medical practice that offer various possibilities for combining the known and the unknown (Weick, 1993; 2005). Thus, the use of routines is incrementally adjusted to experience gained in response to information fed back from results (Cohen et al., 1996; Levitt and March, 1988). Clinical protocols also reveal an inner conflict: when they are closely analysed, the physicians who use them can represent them as both strict and rigid procedures and as a source of flexible action. This dialectical tension activates specific performances from formally restricted but potentially infinite sets of practice possibilities that allow action sequences and originate regular action patterns (Pentland and Reuter, 1994). Doctors follow the rules when necessary and use the rules to protect their improvisations when the rules do not fit. Protocols can then be used to justify both improvisational and non-improvisational approaches. Different professionals, as well as the same professionals in different moments, can activate both the improvisational and the contra-improvisational modes of action without leaving the safety net of the protocol. It may be risky to render the implicit explicit when facing potentially panoptical scrutiny on clinical rounds so tacit knowledge is gradually and implicitly transferred to new organizational members. As an example of this practice, a specialist may call an intern to observe or to perform a technical procedure or an exam, when the specialist finds something rare in an X-ray and considers it an opportunity to witness the discrepancy between what the patient is saying and what the physical symptoms are expressing. This suggests:

Proposition 4: Professionals use bureaucracy as a dual structural resource:

(4a) when appropriate, they complement improvisations with formal sequences in order to comply with standards; 
(4b) when appropriate, they justify their reluctance to improvise with the existence of standardized good practice.

\section{DISCUSSION}

\section{Working with and around clinical guidelines}

Medical work in the emergency room confronts professionals with practical paradoxes that are permanent rather than episodic (Clegg et al., 2002). On the one hand, medical staff use clinical guidelines that aim to (a) assure an adequate level of medical care and (b), prevent liabilities for the organization and its professionals. On the other hand, they work around guidelines via improvisations intended to accommodate particular cases that do not fall under the predictions of the protocol. As one informant put it, "copy/pasting" is not always an effective approach. The process contemplates improvising as an ongoing enacted and situated practice without improvisation as a formal, visible, and reified process.

Several implications can be extracted from the findings. First, "good practice" in the form of protocols, affords formal protection. Second, protocols and formal rules are sometimes used ceremonially, without impeding the local improvisations that tailor practice to specific cases. Protocols thus perform a dual function: they constrain and enable. Metaphorically, doctors can chose to work "online" or "offline": time out is a means for dealing with institutional complexity (e.g. Raaijmakers et al., 2015). Furthermore, coaching young professionals how to work "offline" constitutes an important component of professional socialization.

Previous research has shown that there is more to bureaucracy than habit and rigidity (Briscoe, 2007; Hales, 2002; Olsen, 2005). In confirmation, we note that the same protocols have potentially different 
outcomes, depending on how they are enacted. Protocols may be a source of rigidity and compliance but they do not impede improvisations that undercut bureaucratic institutional logic, as these improvisations unfold "under the radar" (Reay, Golden-Biddle and Germann, 2006, p. 994). In this sense, protocols do not dictate the functioning of the formal organization so much as give professionals the space to nurture and deploy tacit knowledge, not fixed rules.

Bureaucracy does not restrain improvisation but shapes its use and formal expression. Bureaucracies may serve dual roles, depending on the context and intention of their enactment. Protocols establish expectations contained in quality assurance mechanisms and evidence-based practice. They work as institutional tools applied by professional associations and service users in order to emphasize the need for reliability of medical performance (Miller and Bovbjerg, 2002). In response to those influences, organizations implement policies that increase safety and transparency, clarifying operational patterns and reporting systems (Cook et al., 1983; Miller and Bovbjerg, 2002; Smith and Mick, 1985), while physicians may react by both ostensibly adopting and discreetly adapting practice.

Defensive practices lead to the adoption of performative actions marked by ostensive compliance, such as increasing the number of additional exams and referring patients to other specialists (Bowman, 1992; Manner, 2007; Zuckerman, 1984). Although these decisions increase protection, they also result in higher costs, eroding efficiency and consuming time, attention and technology (Kaplan and Porter, 2011). On the other hand, under the veil of the bureaucratic mantle, professionals improvise "under the radar" while complying with protocols. As de Certeau (1984) suggests, established and scrutinized ways of operating coexist with informal ways: micro discipline-inducing protocols coexist with antidisciplinary improvisations (de Certeau, 1984, p. xv). Bureaucratic elements synthesize the potentiality of both coercion and improvisation. Improvisation can persist in organizational environments rich in 
procedural memories, by "deflecting their functioning by means of a multitude of 'tactics' articulated in the details of everyday life" (de Certeau, 1984, p. xiv). Such a perspective is consistent with the recent shift in EBM from "de-emphasizing" individual experts' intuition and knowledge in the clinical practice and instead towards "integrating" it (Tonelli, 1999, 2001) as a way of enacting "interpretive judgement" (Feinstein and Horwitz, 1997) and a "casuistic approach" (Tonelli, 2006). Such considerations support a final and integrative proposition:

Proposition 5: Bureaucracy allows professionals to enact their behaviour in a context framed by the apparent conflict of a dual logic:

(5a) by following performative procedures, bureaucracy permits professionals to express compliance and provides shelter in an increasingly scrutinising environment;

(5b) while respecting the formal protocols, bureaucracy allows professionals to improvise on the basis of tacit knowledge, experience and professional intuition, and thus permits personalized care.

There is an "organizational underlife" (Manning, 2008), a space in which experiments might be conducted outside the dominant logic, outside formal organizational controls. Such an "underlife" favours the unfolding of improvisation (improvising) over formalized procedures, the creation of "hidden transcripts" and the stabilization of discourses "beyond direct observation of those in power" (Dailey and Browning, 2014, p. 24). In summary, experts use the resources of a bureaucratic system to develop wisdom (Weick, 1995): they synthesize explicit knowledge captured in formal protocols with tacit knowledge resulting from experience. That is consistent with what Sackett et al. (1996, p. 72) posit: 
"good doctors use both individual clinical expertise and the best external evidence, and neither alone is enough."

The novelty of this contribution derives from the fact that the existence of ostensive compliance and underlife improvisation create a "zone of operability" in which compliance and intuition both preserve their self-standing "centrality" (contested logics) while converging toward a state of "alignment", with the synthesis providing ground for "compatible prescriptions for actions" (Besharov and Smith, 2014). To this extent, EBM focuses only on the centrality of compliance to standards, considering intuition as the necessary, although unwelcome, complementary trigger for enacting medical practice. As Tonelli (2006, p. 252) suggests, "the major problem with experiential knowledge is that it is prone to multiple kinds of cognitive bias (Elstein and Schwarz, 2002), with potentially false conclusions about causality of treatment effect being drawn." The fact that improvising unfolds as practice even in fields in which improvisation is not defended sheds light on a new a synthesis of uniformity (adoption) and variation (adaptation) (Fig. 2). In a field subject to institutional complexity, the act of improvising allows clinicians to exploit their expertise and experience at their best, yet under the shelter of formal compliance. To this extent the practice of improvising in the emergency room displays how the enacted behaviours activate a process of "logic blending", as Binder (2007) terms it, which integrates the coexistence of conflicting logics (McPherson and Sauder, 2013). Furthermore, the enactment of improvising within prescription responds to (and substantiates) the call for the adoption of a "casuistic" approach to care coming from some of the medical literature (e.g. Tonelli, 2006).

On the developmental side, mentoring new doctors consists in helping them learn how and when to use discretion, how to use the system to circumvent the system's impositions. If guidelines might be seen as "strategies" embedding the "power of [scientific] knowledge" (e.g. EBMWG, 1992), improvisation is 
"tactic" knowing; however, in this context it is hardly "the art of the weak" (de Certeau 1984, p. 36-37) because it is only the most experienced clinicians that improvise rather than the interns and least experienced. To this extent, understanding such phenomena illuminates an apparent minority of extreme deviations whose practice sits outside and on top of a majority of behaviours (de Certeau, 1984).

\section{Limitations and avenues for future research}

The major limitation concerns generalization: statistical generalization (from observation to population) is problematic but analytical generalization (from observation to theory) may not constitute an issue (Gibbert and Ruigrok, 2010). Most improvisations observed corresponded with Weick's (1998) "interpretations", minor liberties, rather than visibly significant improvisations. Different services, organizations and sectors may present diverse patterns of improvisational behaviour. Attempts at generalizing from the results should thus be made with caution (Eisenhardt and Graebner, 2007).

In terms of practice, pushing EBM too far may be against the best interests of both the profession and the patient. As Maynard (1997) defended, EBM is an "incomplete method for informing treatment choices" (p. 126), and clinicians should "accept that evidence-based medicine is only part of the decision-making process about the allocation of resources" (p. 128). Such a concern resonates with Vaill's (1982, p. 35) warning that “the possibility of a 'high-performing relationship' with an immediate client is sometimes a secondary consideration compared with adhering to professional standards."

Key questions should be considered in future research: might the push for evidence-based practice potentially lead to less heedful medical care? Might it reduce efficiency due to the batteries of exams and tests that are conducted as defensive and standardized practices aimed at self-protection? Does standardization diminish perceptions of professional empowerment and accountability? If this is so, at 
what cost does it do so? Is it the case that standardization invites depersonalized and less humane healthcare? Can legitimate improvisations be a factor for consideration in training medical practice? These questions, instead of the randomized trials, put the individuals at the milieu of the discourse. As Morrell, Learmonth, and Heracleous (2015 p. 529) put it: "fundamental problems remain with evidencebased management. ... [as] the evidence-based approach relegates narrative to a ghetto category of knowledge, but it is itself a narrative."

\section{CONCLUSION}

Medical practice, as well as management practice, may be at the crossroads between the push for evidence-based approaches and a pull from adoption of routine application of best practices (e.g. Tourish, 2013). Scientific progress, growing professionalization and public scrutiny imply a synthesis of explicit, codified knowledge and tacit, intuition-based knowledge. Because best practices do not match the singularity of the situated case, a physician that applies evidence-based good practice without considering the idiosyncrasies of patients is possibly no better than the manager that adopts managerial technologies without caring about the specificities of the organization. We observed that professionals in the heavily regulated bureaucracy of a certified hospital respond to increasing institutionalization of EBM by enacting their work as a combination of ostensive compliance and underlife improvisation, in different degrees, depending on experience and contingency.

In this way, professionals respond both to macro-institutional constraints and to the situational requirements they face in their everyday job requirements. These micro mechanisms expose clinicians to conflicting logics: they defer to an institutional logic of standards while in their institutional work they improvise. There is no paradox in this conjunction because it allows professionals simultaneously to maintain the status quo while escaping its coercive tentacles. They express compliance while preserving 
autonomy. Responding to our research question, we conclude that the fabric of bureaucracy contains the potentiality for the production of improvisation as the fruit of a relational dialectic between structure and freedom (Clegg et al., 2002). Improvisation unfolds though prescription and happens in the bureaucratic underlife, in such a way that it is congruent with the preservation of the institutional façade, therefore reinforcing standards but also allowing improvisation. In so doing, it protects professional empowerment in "messy, indeterminate situations" (Schön, 1987, p. 4) which, without compromising the professional standards that emerge from EBM, calls forth professional improvisation (Frankford, Patterson and Konrad, 2000) while preserving professional protection against risks emerging from an increasingly scrutinized context of professional practice. 


\section{REFERENCES}

Adler, P. S. and S. W. Kwon (2013). 'The mutation of professionalism as a contested diffusion process: Clinical guidelines as carriers of institutional change in medicine', Journal of Management Studies, 50, pp. 930-962.

Argote, L. (1982). 'Input uncertainty and organizational coordination in hospital emergency units', Administrative Science Quarterly, 27, pp. 420-434.

Alvesson, M. (2003). 'Beyond neopositivists, romantics and localists: A reflexive approach to interviews in organizational research', Academy of Management Review, 28, pp. 13-33.

Barros, P. P. and J. A. Simões (2007). 'Portugal: Health system review', Health Systems in Transition, 9, pp. 1-140.

Battista, R. N., Hodge, M. J. and P. Vineis (1995). 'Medicine, practice and guidelines: The uneasy juncture of science and art', Journal of Clinical Epidemiology, 48, pp. 875-880.

Besharov, M. L. and W. K. Smith (2014). 'Multiple institutional logics in organizations: Explaining their varied nature and implications', Academy of Management Review, 39, pp. 364-381.

Binder, A. (2007). 'For love and money: Organizations' creative responses to multiple environmental logics', Theory and society, 36, pp. 547-571.

Bowman, M. A. (1992). 'Risk management and medical malpractice', American Family Physician, 45, pp. $1741-1745$.

Brickerhoff, D. (2003). Accountability and Health Systems: Overview, Framework, and Strategies. 
Tulane University School of Public Health and Tropical Medicine University Research Co., LLC, http://www.who.int/management/partnerships/accountability/AccountabilityHealthSystemsOvervi ew.pdf, accessed at 30.07.15.

Burke, L. A. and M. K. Miller (1999). 'Taking the mystery out of intuitive decision making', The Academy of Management Executive, 13, pp. 91-99.

Briscoe, F. (2007). 'From iron cage to iron shield? How bureaucracy enables temporal flexibility for professional service workers', Organization Science, 18, pp. 297-314.

Brown, S. L. and K. M. Eisenhardt (1997). 'The art of continuous change: Linking complexity theory and time-paced evolution in relentlessly shifting organizations', Administrative Science Quarterly 42, pp. 1-34.

Chiva, R. and J. Alegre (2009). 'Organizational learning capability and job satisfaction: An empirical assessment in the ceramic tile industry', British Journal of Management, 20, pp. 323-340.

Clegg, S. R., Cunha, J. V. and M. P. Cunha (2002). 'Management paradoxes: A relational view', Human Relations, 55, pp. 483-503.

Cohen, M. D., Burkhart, R., Dosi, G., Egidi, M., Marengo, L., Warglien, M. and S. Winter (1996). 'Routines and other recurring action patterns of organizations: Contemporary research issues', Industrial and Corporate Change, 5, pp. 653-698.

Cook, K., Shortell, S. M., Conrad, D. A. and M. A. Morrisey (1983). 'A theory of organizational response to regulation: The case of hospitals', Academy of Management Review, 8, pp. 193-205. 
Corbin, J. and A. Strauss (1990). 'Grounded theory research: Procedures, canons, and evaluative criteria', Qualitative Sociology, 13, pp. 3-21.

Cornelissen, J. P., Mantere, S. and E. Vaara (2014). 'The contraction of meaning: the combined effect of communication, emotions, and materiality on sensemaking in the Stockwell shooting', Journal of Management Studies, 51, pp. 699-736.

Crossan, M. M. and M. Sorrenti (1997). 'Making sense of improvisation', Advances in Strategic Management, 14, pp. 155-180.

Cunha, M. P., Clegg, S. R. and K. Kamoche (2006). 'Surprises in management and organization: Concept, sources and a typology', British Journal of Management, 17, pp. 317-329.

Cunha, M. P., Cunha, J. V. and K. Kamoche (1999). 'Organizational improvisation: What, when, how and why', International Journal of Management Reviews, 1, pp. 299-341.

Cunha, M. P., Miner A. S. and E. Antonacopoulou (2016). 'Improvisation processes in organizations'. In A. Langley and H. Tsoukas (eds), The Sage Handbook of Process Organization Studies. London: Sage. In press.

Cunha, M. P., Neves, P., Clegg, S. R. and A. Rego (2014). 'Tales of the unexpected: discussing improvisational learning', Management Learning. In press: DOI: 10.1177/1350507614549121

Dailey, S. L. and L. Browning (2014). 'Retelling stories in organizations: Understanding the functions of narrative repetition', Academy of Management Review, 39 (1), pp. 22-43.

Dane, E. and M. G. Pratt (2007). 'Exploring intuition and its role in managerial decision making', 
Academy of Management Review, 32, pp. 33-54.

de Certeau, M. (1984). The practice of everyday life. Berkeley, CA: University of California Press.

D’Aunno, T., Succi, M. and J. A. Alexander (2000). 'The role of institutional and market forces in divergent organizational change', Administrative Science Quarterly, 45, pp. 679-703.

Denis, J. L., Lamothe, L. and A. Langley (2001). 'The dynamics of collective leadership and strategic change in pluralistic organizations', Academy of Management Journal, 44, pp. 809-837.

DiMaggio, P. J. and W. W. Powell (1983). 'The iron cage revisited: Institutional isomorphism and collective rationality in organizational fields', American Sociological Reviews, 48, pp. 147-160.

Dunn, M. B. and C. Jones, C. (2010). 'Institutional logics and institutional pluralism: The contestation of care and science logics in medical education, 1967-2005', Administrative Science Quarterly, 55, pp. 114-149.

Ebbers, J. J. and N. M. Wijnberg (2009). 'Organizational memory: From expectations memory to procedural memory', British Journal of Management, 20, pp. 478-490.

EBMWG - Evidence Based Medicine Working Group (1992). 'Evidence-Based Medicine: a new approach to teaching the practice of medicine', JAMA, 268, pp. 2420-2425.

Editorial. (2012). ‘Ending violence against doctors in China', Lancet, 379, p. 1764.

Edmondson, A. C., Bohmer, R. M. and G. P. Pisano (2001). 'Disrupted routines: Team learning and new technology implementation in hospitals', Administrative Science Quarterly, 46, pp. 685-716. 
Eisenhardt, K. M. (1989). 'Making fast strategic decisions in high-velocity environments', Academy of Management Journal, 32, pp. 553-576.

Eisenhardt, K. M. and M. E. Graebner (2007). 'Theory building from cases: Opportunities and challenges', Academy of Management Journal, 50, pp. 25-32.

Elmore, J. G., Taplin, S. H., Barlow, W. E., Cutter, G. R., D’Orsi, C. J., Hendrick, R. E., Abraham, L. A., Fosse, J. S. and P. A. Carney (2005). 'Does litigation influence medical practice? The influence of community radiologists' medical malpractice perceptions and experience on screening mammography', Radiology, 236, pp. 37-46.

Elstein, A. S. and A. Schwarz (2002). 'Clinical problem solving and diagnostic decision making: Selective review of the cognitive literature'. BMJ, 324, pp. 729-732.

Evanschitzky, H., Ahlert, D., Blaich, G. and P. Kenning (2007). 'Knowledge management in knowledge-intensive service networks: a strategic management approach', Management Decision, 45, pp. 265-283.

Faraj, S. and Y. Xiao (2006). 'Coordination in fast-response organizations', Management Science, 52, pp. $1155-1169$.

Farjoun, M. (2010). 'Beyond dualism: Stability and change as duality', Academy of Management Review, 35, pp. 202-225.

Feder, G., Eccles, M., Grol, R., Griffiths, C. and J. Grimshaw (1999). 'Using clinical guidelines', BMJ, 318, pp. 728-730. 
Feinstein, A. R. and R. I. Horwitz (1997). 'Problems in the «evidence» of «evidence-based medicine»', The American Journal of Medicine, 103, pp. 529-535.

Ferlie, E. B. and S. M. Shortell (2001). 'Improving the quality of health care in the United Kingdom and the United States: A framework for change', Milbank Quarterly, 79, pp. 281-315.

Friedland, R. and R. R. Alford (1991). 'Bringing society back in: symbols, practices and institutional contradictions'. In W. W. Powell and P. J. DiMaggio (eds.), The new institutionalism in organizational analysis, pp. 232-263. Chicago: Chicago University Press.

Frankford, D. M., Patterson, M. A., and T. R. Konrad (2000). 'Transforming practice organizations to foster lifelong learning and commitment to medical professionalism', Academic Medicine, 75, pp. 708-717.

Garfield, F. B. and J. M. Garfield (2000). 'Clinical judgment and clinical practice guidelines', International Journal of Technology Assessment in Health Care, 16, pp. 1050-060.

Gibbert, M. and W. Ruigrok (2010). 'The "what" and "how" of case study rigor: Three strategies based on published work', Organizational Research Methods, 13, pp. 710-737.

Gittell, J. H. and A. Douglass (2012). 'Relational bureaucracy: Structuring reciprocal relationships into roles', Academy of Management Review, 37, pp. 709-733.

Glaser, B. G. and A. L. Strauss (1967). The discovery of grounded theory: Strategies for qualitative research. Chicago: Aldine.

Greenwood, R., Hinings, C. R. and D. Whetten, (2014). 'Rethinking institutions and organizations', 
Journal of Management Studies, 51, pp. 1206-1220.

Guillén, M. F. (2001), The limits of convergence: Globalization and organizational change in Argentina, South Korea, and Spain. Princeton, NJ: Princeton University Press.

Hadders, H. (2009). 'Medical practice, procedure manuals and the standardisation of hospital death', Nursing Inquiry, 16, pp. 22-32.

Hadida, A. L. and W. Tarvainen (2014). 'Organizational Improvisation: a consolidating review and framework', International Journal of Management Reviews. In press: DOI: 10.1111/ijmr.12047

Haidet P. (2007). 'Jazz and the 'art' of medicine: Improvisation in the medical encounter', Annals of Family Medicine, 5, pp. 164-169.

Hales, C. (2002). '«Burocracy-lite» and continuities in managerial work', British Journal of Management, 13, pp. 51-66.

Halligan, A. and L. Donaldson (2001). 'Implementing clinical governance: Turning vision into reality', British Medical Journal, 322, pp. 1413-1417.

Hiyama, T., Yoshihara, M., Tanaka, S., Urabe, Y., Ikegami, Y., Fukuhara, T. and K. Chayama (2006). 'Defensive medicine practices among gastroenterologists in Japan', World Journal of Gastroenterology, 12, pp. 7671-7675.

Janicek, M. (2006). 'The hard art of soft science: Evidence-based medicine, reasoned medicine or both?', Journal of Evaluation in Clinical Practice, 12, pp. 410-419.

Kamoche, K. and M. P. Cunha (2001). 'Minimal structures: From jazz improvisation to product 
innovation', Organization Studies, 22, pp. 733-764.

Kaplan, R. S. and M. E. Porter (2011). 'How to solve the cost crisis in health care', Harvard Business Review, 89, pp. 47-64.

Kenny, N. P. (1997). 'Does good science make good medicine? Incorporating evidence into practice is complicated by the fact that clinical practice is as much art as science', Canada Medical Association Journal, 157, pp. 33-36.

King, A. W. and A. L. Ranft (2001). 'Capturing knowledge and knowing through improvisation: What managers can learn from the thoracic surgery board certification process', Journal of Management, 27, pp. 255-277.

Kirmayer, L. J. (1994). 'Improvisation and authority in illness meaning', Culture, Medicine and Psychiatry, 18, pp. 183-214.

Kraatz, M. S. and E. S. Block (2008). 'Organizational implications of institutional pluralism'. In R. Greenwood, C. Oliver, R. Suddaby and K. Sahlin-Andersson (eds), The Sage handbook of organizational institutionalism, pp. 243-275. London: SAGE.

Langley, A., Smallman, C., Tsoukas, H. and A. H. Van de Ven (2013). 'Process studies of change in organization and management: unveiling temporality, activity, and flow', Academy of Management Journal, 56, pp. 1-13.

Levitt, B. and J. G. March (1988). 'Organizational learning', Annual Review of Sociology, 14, pp. 319340. 
Locke, K. (2001). Grounded theory in management research. London: Sage.

Maia, A. (2011). 'Redução de ecografias e outros exames poupa até 692 milhões', Diário de Notícias, December 3, p. 16.

Malterud, K. (2001). 'The art and science of clinical knowledge: evidence beyond measures and numbers', The Lancet, 358, pp. 397-400.

Manner, P. A. (2007). 'Practicing defensive medicine - Not good for patients or physicians', AAOS Now, 1 : http://www.aaos.org/news/bulletin/janfeb07/clinical2.asp.

Manning, P. K. (2008). 'Goffman on organizations', Organization Studies, 29, pp. 677-699.

Marshall, T. (1997). 'Scientific knowledge in medicine: A new clinical epistemology?', Journal of Evaluation in Clinical Practice, 3, pp. 133-138.

Maynard, A. (1997). 'Evidence-based medicine: an incomplete method for informing treatment choices', The Lancet, 349, pp. 126-128.

McPherson, C. M. and M. Sauder (2013). 'Logics in action managing institutional complexity in a drug court', Administrative Science Quarterly, 58, pp. 165-196.

Meyer, R. E. and M. A. Höllerer (2014). 'Does Institutional Theory Need Redirecting?', Journal of Management Studies, 51, pp. 1221-1233.

Miller, R. H. and R. R. Bovbjerg (2002). 'Efforts to improve patient safety in large, capitated medical groups: Description and conceptual model', Journal of Health Politics, Policy and Law, 27, pp. 401-440. 
Miller, W. L., McDaniel Jr., R. R., Crabtree, B. F. and K. Stange (2001). 'Practice jazz: Understanding variation in family practices using complexity science', Journal of Family Practice, 50, pp. 872878.

Mintzberg, H. (1983). Structuring in fives: Designing effective organization. Englewood Cliffs, NJ: Prentice-Hall.

Moorman, C. and A. Miner (1998a). 'The convergence between planning and execution: Improvisation in new product development', Journal of Marketing, 62, pp. 1-20.

Moorman, C. and A. S. Miner (1998b). 'Organizational improvisation and organizational memory', Academy of Management Review, 23, pp. 698-723.

Morrell, K., Learmonth, M. and L. Heracleous (2015). 'An archaeological critique of 'Evidence-based Management': One digression after another', British Journal of Management, 26, pp. 529-543.

Mykhalovskiy, E. and L. Weir (2004). 'The problem of evidence-based medicine: Directions for social science', Social Science \& Medicine, 59, pp. 1059-069.

Naylor, C. D. (2001). 'Clinical decisions: From art to science and back again', The Lancet, 358, pp. 523524.

Nicolini, D. (2010). 'Medical innovation as a process of translation: A case from the field of telemedicine', British Journal of Management, 21, pp. 1011-1026.

Olsen, J. P. (2005). 'Maybe it is time to rediscover bureaucracy', Journal of Public Administration Research, 16, pp. 1-24. 
Pentland, B. T. and H. H. Reuter (1994). 'Organizational routines as grammars of action', Administrative Science Quarterly, 39, pp. 484-510.

Pfeffer, J. (1994). 'The costs of legalization: The hidden dangers of increasingly formalized control'. In S. B. Sitkin and R. J. Bies (eds), The legalistic organization, pp. 329-346. Thousand Oaks, CA: Sage.

Perrow, C. (1986). Complex Organizations: A Critical Essay, $3^{\text {rd }}$ edn. New York: Random House.

Raaijmakers, A. G. M., Vermeulen, P. A. M., Meeus, M. T. H. and C. Zietsma (2015). 'I need time! Exploring pathways to compliance under institutional complexity', Academy of Management Journal, 58, pp. 85-110.

Reay, T., Golden-Biddle, K. and K. Germann (2006). 'Legitimizing a new role: Small wins and microprocesses of change', Academy of Management Journal, 49, pp. 977-998.

Reay, T. and C. R. Hinings (2009). 'Managing the rivalry of competing institutional logics', Organization Studies, 30, pp. 629-652.

Roter, D. L., Stewart, M., Putnam, S.M., Lipkin, M. Jr., Stiles, W. and T.S. Inui (1997). 'Communication patterns of primary care physicians', Journal of the American Medical Association, 277, pp. 350-356.

Sackett, D. L. and W. M. C. Rosenberg (1995). 'On the need for evidence-based medicine', Journal of Public Health Medicine, 17, pp. 330-334.

Sackett, D. L., Rosenberg, W., Gray, J. A., Haynes, R. B., and W. S. Richardson (1996). 'Evidence 
based medicine: What it is and what it isn't', BMJ, 312, pp. 71-72.

Sagiv, L., Arieli, S., Goldenberg, J. and A. Goldschmidt (2009). 'Structure and freedom in creativity: The interplay between externally imposed structure and personal cognitive style', Journal of Organizational Behaviour, 31, pp. 1086-1110.

Saunders, J. (2000). 'The practice of clinical medicine as an art and as a science', Medical Humanities, 26, pp. 18-22.

Schön, D. A. (1987). Educating the reflective practitioner: Toward a new design for teaching and learning in the professions. San Francisco, CA: Jossey-Bass.

Scott, W. R. (2001). Institutions and organizations: ideas and interests, $2^{\text {nd }}$ edn. Thousand Oaks, CA: Sage.

Shahar, E. (1997). 'A Popperian perspective of the term 'evidence-based medicine', Journal of Evaluation in Clinical Practice, 3, pp. 109-116.

Sharma, V., Dowd, M. D., Swanson, D. S., Slaughter, A. J. and S. D. Simon (2003). 'Influence of the news media on diagnostic testing in the emergency unit', Archives of Pediatrics \& Adolescent Medicine, 157, pp. 257-260.

Shaughnessy, A.F., Slawson, D.C. and L. Becker (1998). 'Clinical jazz: harmonizing clinical experience and evidence-based medicine', Journal of Family Practice, 47, pp. 425-428.

Smith, H. L. and S. S. Mick (1985). 'A theory of organizational response to regulation: A reply', Academy of Management Review, 10, pp. 332-336. 
Sonenshein, S., DeCelles, K. and J. Dutton (2014). 'It's not easy being green: Self-evaluation and their role in explaining support of environmental issues', Academy of Management Journal, 57, pp. 737.

Strauss, A. and J. Corbin (1998). Basics of qualitative research: Techniques and procedures for developing grounded theory, $2^{\text {nd }}$ edition. London: Sage.

Studdert, D. M., Mello, M. M., Sage, W. M., DesRoches, C. M., Peugh, J., Zapert, K. and T. A. Brennan (2005). 'Defensive medicine among high-risk specialist physicians in a volatile malpractice environment', Journal of the American Medical Association, 293, pp. 2609-2617.

Suddaby, R. (2006). 'From the editors: What grounded theory is not', Academy of Management Journal, 49, pp. 633-642.

Summerton, N. (1995). 'Positive and negative factors in defensive medicine: A questionnaire study of general practitioners', BMJ, 310, pp. 27-29.

Tonelli, M. R. (1999). 'In defense of expert opinion', Academic Medicine, 74, pp. 1187-92.

Tonelli, M. R. (2001). 'The limits of evidence-based medicine', Respiratory Care, 46, pp. 1435-40.

Tonelli, M. R. (2006). 'Integrating evidence into clinical practice: An alternative to evidence-based approaches', Journal of Evaluation in Clinical Practice, 12, pp. 248-256.

Tourish, D. (2013). “"Evidence based management” or "evidence oriented organizing”? A critical realist perspective', Organization, 20, pp. 173-192.

Tucker, A. L. and A. C. Edmondson (2003). 'Why hospitals don’t learn from failures: Organizational 
and psychological dynamics that inhibit system change', California Management Review, 45, pp. $55-72$.

Vaill, P. B. (1982). 'The purposing of high-performing systems', Organizational Dynamics, 11, pp. 2339.

Vogus, T. J., Sutcliffe, K. M. and K. E. Weick (2010). 'Doing no harm: Enabling, enacting, and elaborating a culture of safety in health care', Academy of Management Perspectives, 24, pp. 6077.

Weick, K. E. (1988). 'Enacted Sensemaking in Crisis Situations', Journal of Management Studies, 25, pp. 305-317.

Weick, K. E. (1990). 'The vulnerable system: an analysis of the Tenerife air disaster', Journal of Management, 16, pp. 571-593.

Weick, K. E. (1993). 'The collapse of sensemaking in organizations: the Mann Gulch disaster', Administrative Science Quarterly, 38, pp. 628-652.

Weick, K. E. (1995). 'South Canyon revisited: Lessons from high reliability organizations', Wildfire, 4, pp. 54-68.

Weick, K. E. (1998). 'Improvisation as a mindset for organizational analysis', Organization Science, 9, pp. 543-555.

Weick, K. E. (2005). 'Managing the unexpected: Complexity as distributed sensemaking'. In R. R. McDaniel, Jr. and D. J. Drieb (eds), Uncertainty and surprise in complex systems: Questions on 
working with the unexpected, pp. 51-65. Berlin: Springer-Verlag.

Weick, K. E. and K. M. Sutcliffe (2003). 'Hospitals as cultures of entrapment: A re-analysis of the Bristol Royal Infirmary', California Management Review, 45, pp. 73-84.

Weick, K. E. and K. M. Sutcliffe (2007). Managing the unexpected: Resilient performance in an age of uncertainty, $2^{\text {nd }}$ edition. San Francisco: Jossey-Bass.

Woolf, S. H., Grol, R., Hutchinson, A., Eccles, M. and J. Grimshaw (1999). 'Clinical guidelines: potential benefits, limitations, and harms of clinical guidelines', BMJ, 318, p. 527-530.

Welch, S. J., Stone-Griffith, S., Asplin, B., Davidson, S. J., Augustine, J. and J. D. Schuur (2011). 'Emergency department operations dictionary: Results of the second performance measures and benchmarking summit', Academic Emergency Medicine, 18, pp. 539-544.

Zuckerman, S. (1984). 'Medical malpractice: Claims, legal costs, and the practice of defensive medicine', Health Affairs, 3, pp. 128-133. 
TABLE 1

\section{Field research timeline}

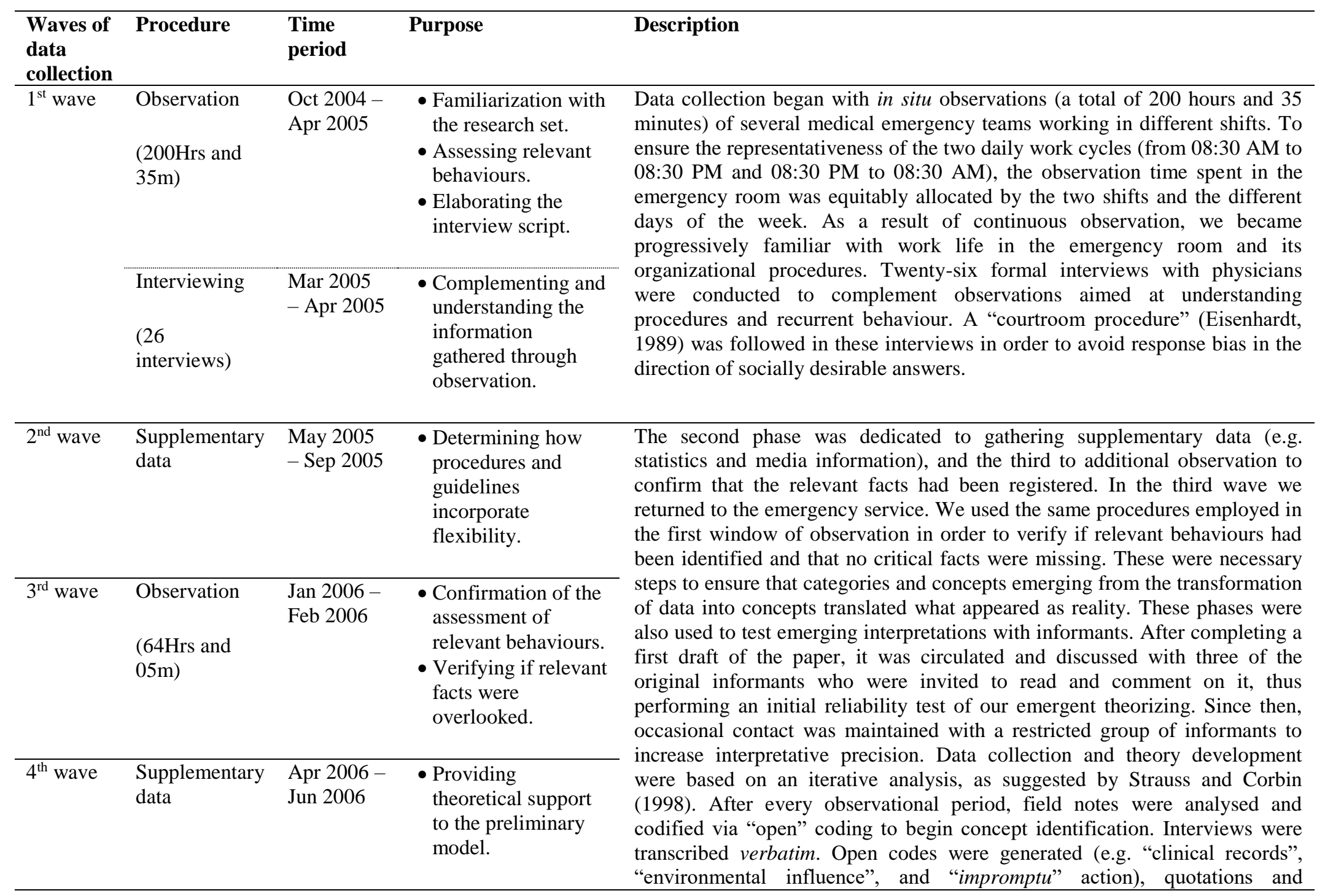


relationships between relevant concepts were summarized to be more useable in concept identification and in the development of progressive conceptual depth and abstraction. Data collection continued over a period of five months to improve understanding of improvisation in the emergency room. Internal and external documents explaining rules, procedures, and algorithms that support medical practice in emergency situations were consulted. With this information, a constant comparative analysis between data and theory was conducted to identify meaningful patterns in conceptual clusters. ${ }^{*}$ A further wave of data collection gathered additional archival information and public documents that complemented the tentative categories emerging from the data analysis to refine and verify existing categories.



*Note: In the process, we contacted the Ordem dos Médicos (the Portuguese Medical Association, the mandatory membership association for practicing physicians) to obtain data on medical complaints from 1997 onwards, when the data series started. We did this based on observations of some patient behaviour in the emergency room and because of recurring references by professionals in interviews to "defensive medical practice" (i.e., practice intended to minimize the future possibility of malpractice liability). A representative of the Ordem dos Médicos reinforced the importance of checking medical complaints by stating "In 
Portugal, defensive medicine is common practice" (in Maia, 2011, p.16). Simultaneously, public documents (e.g. newspaper articles and statistical reports) that were directly related to patient complaints, lawsuits, and medical procedures were analysed (e.g. "Professional scrutiny"). 


\section{FIGURE 1}

\section{General data framework}

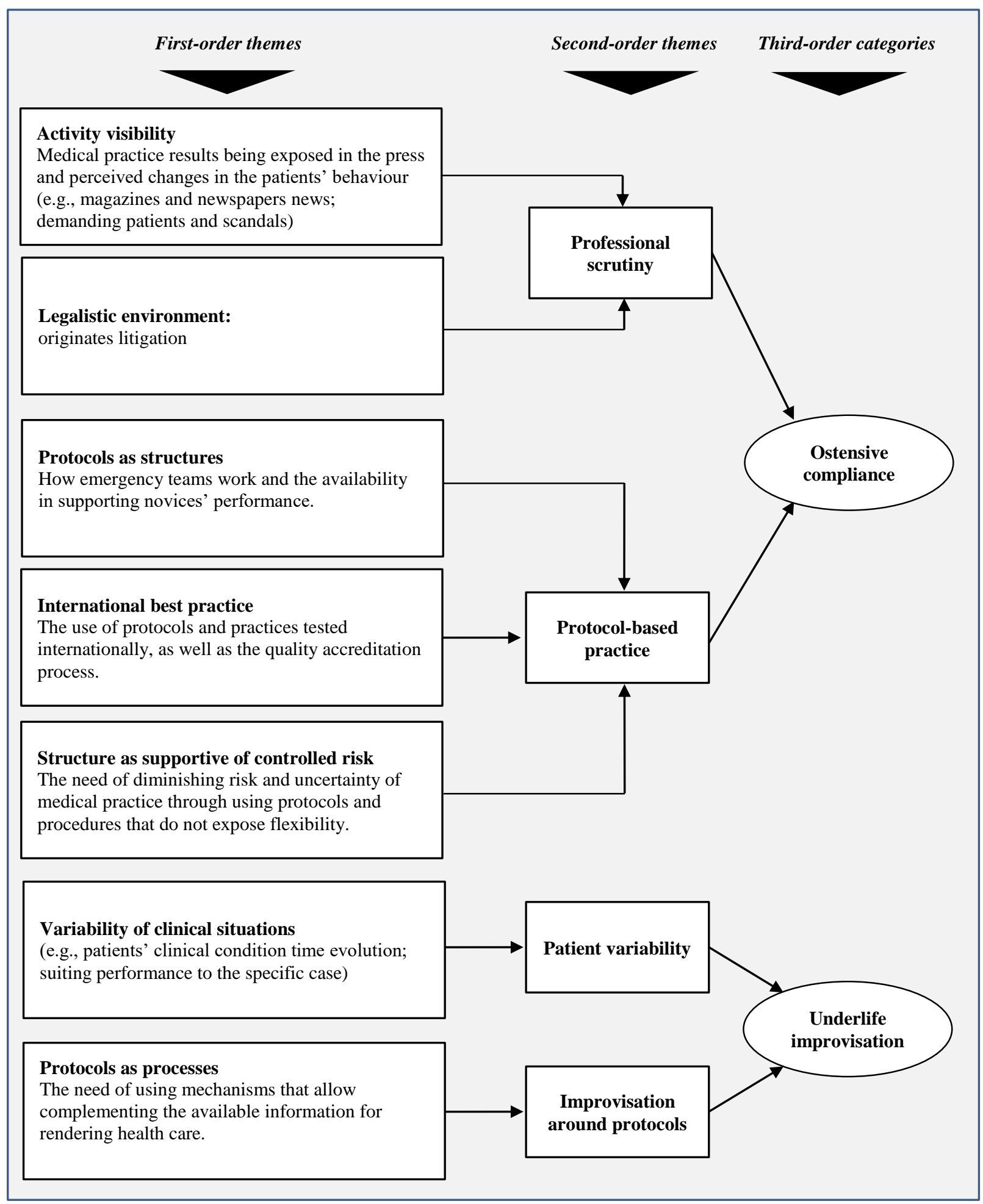




\section{FIGURE 2}

A model of improvisation in a highly institutionalized setting

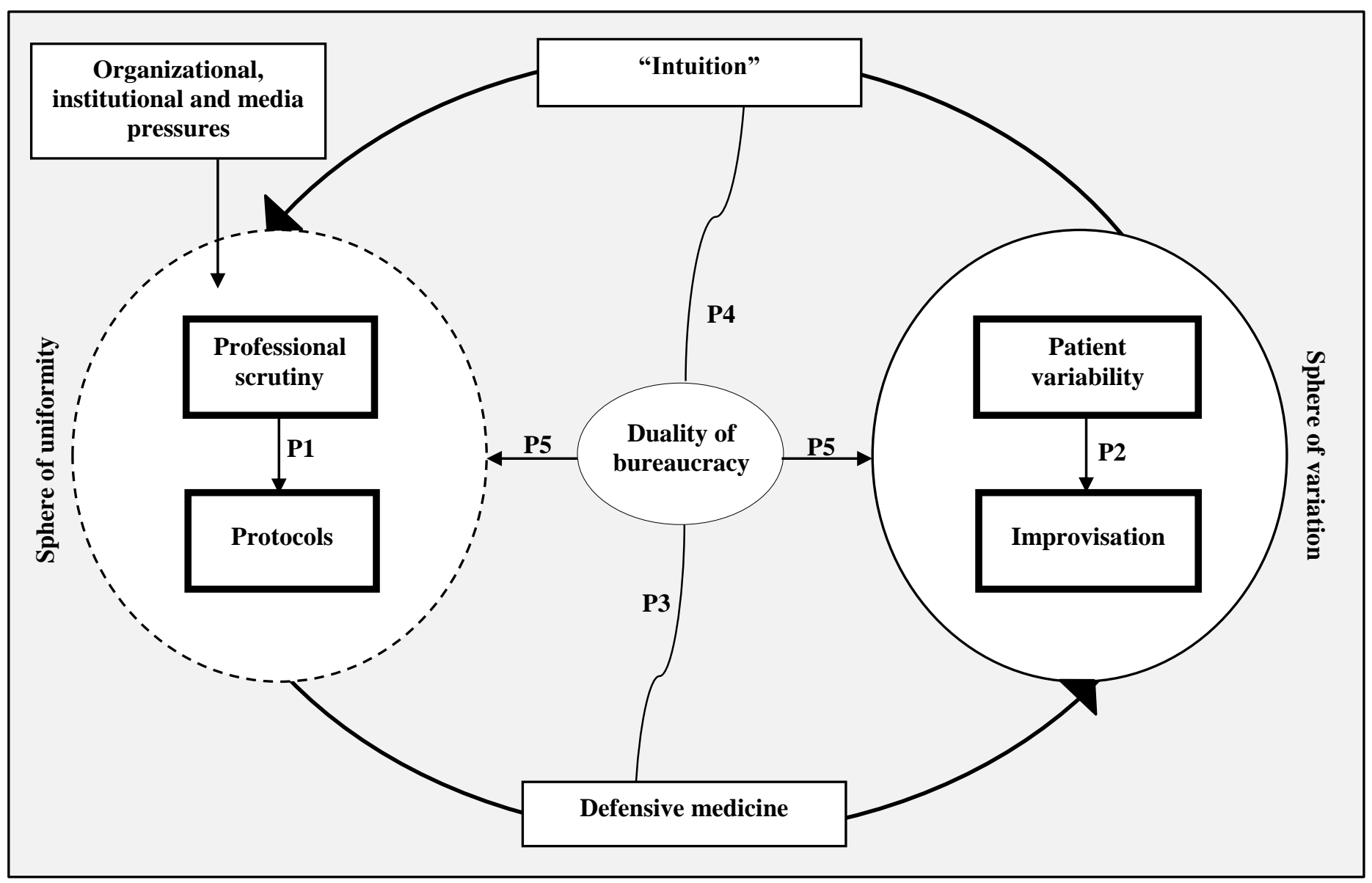




\section{FOOTNOTES}

i The clearness of such a "paradigmatic shift" is not unanimous though, since some other authors argues that in Popperian terms EBM itself is not distinguishable from "medicine" (Shahar, 1997).

ii Kirmayer (1994, p. 183) supports this view of clinical practice: "While authority is necessary to provide a structure on which variations of meaning can be improvised, authoritative meanings may also restrict the possibilities for invention by clinician and patient. The goal of patient and physician is to create enough certainty to diminish the threat of the inchoate while preserving enough ambiguity to allow for fresh improvisation. Accounts of illness meaning must recognize the interdependence of normative rigidity and metaphoric invention".

iii The category "Professional scrutiny" emerged from observation and interviews, complemented by data obtained from Ordem dos Médicos, the Sindicato Independente dos Médicos (the most representative physicians' union) and from independent media. 